\title{
The Thermal Ecology of Snakes in Bertoua Municipality, Eastern Region, Cameroon
}

\author{
Maurice ME*, Mengwi NH, Okon OA, Lengha TK and Ayamba NS \\ Department of Environmental Science, Faculty of Science, University of Buea, \\ Cameroon
}

*Corresponding author: DR Melle Ekane Maurice, Department of Environmental Science, Faculty of Science, University of Buea, BUEA, P.O.BOX. 63, Cameroon, Tel: +237675393156; Email: melleekane@gmail.com

\section{Research article \\ Volume 3 Issue 4}

Received Date: September 20, 2019

Published Date: October 25, 2019

DOI: $10.23880 /$ jenr- 16000175

\section{Abstract}

Climate generally and temperature in particular have long been recognized as important determinants of the distribution, abundance, and activity of animals. Thus, the maintenance of appropriate body temperatures affects both the fitness of individual snakes and the viability of their populations. Thermoregulation is probably the most important factor affecting habitat selection in snakes. Hence, this study is aimed at exploring the role of weather condition to the ecological niche of snakes in Bertoua forest area. The research data collection was done by the use of check-sheets for a period of one month from 7:30am-5:30pm each day in the forest area of Bertoua. A random spot observation of 444 snakes was made on 6 species, black cobras (Naja melanoleuca), green mambas (Dendroaspis viridis), vipers (Bitis gabonica), green-tree snakes (Dendrelaphis punctulatus), small brown snakes (Dendrelaphis shokan), and python (Python regius). Ecological factors such as weather condition, vegetation, landscape, location, and photo-period were also taken into account. The survey revealed an ecological relationship between weather condition and various species of snakes in the study area, $\chi^{2}=11.244 \mathrm{df}=10, \mathrm{P}<0.05$. Besides, the results revealed an association between landscape and snake species $\chi^{2}=21.142 \mathrm{df}=15 \mathrm{P}<0.05$. Moreso, photo-period significantly associated with weather condition, $\chi^{2}=8.907 \mathrm{df}=4, \mathrm{P}<0.05$. The location of snakes significantly associated with the species, $\chi^{2}=191.344 \mathrm{df}=5$, $\mathrm{P}=0.00$. Furthermore, snake location and weather condition revealed a significant link, $\chi^{2}=5.546 \mathrm{df}=2, \mathrm{P}<0.05$. Finally, weather condition and landscape showed a significant dependency, $\chi^{2}=41.316 \mathrm{df}=6, \mathrm{P}=0.00$. Reptiles are found in a range of diverse environments from the arctic to the equator. Their success and dispersion is dependent on access to external heat sources for their internal processes to operate sufficiently such as homeostasis.

Keywords: Climate; Temperature; Thermoregulation; Ecological niche; Snakes; Habitat selection 


\section{Introduction}

The importance of body temperature to reptiles accounts for herpetologists' enduring interest in thermal ecology [1]. Temperature affects everything from specific functions such as ecdysis and embryonic development to more general functions such as digestion, recovery from injury, growth, and locomotion $[1,2]$. Thus, the maintenance of appropriate body temperatures affects both the fitness of individual snakes and the viability of their populations. Given that thermoregulation is probably the most important factor affecting habitat selection in snakes $[3,4]$, any environmental perturbation that alters snakes' abilities to maintain preferred body temperatures will be a conservation concern.

Climate generally and temperature in particular have long been recognized as important determinants of the distribution, abundance, and activity of animals [5]. Thus, the warming of global climates is causing growing concern about how climate change affects natural populations [6,7]. Predicting how a population will respond to warmer climates requires knowledge of how the important demographic features of the population vary in response to current climatic variation. Responses to global warming include short-term effects on populations (changes in abundance) and long-term effects that result in shifts in species' distributions [8]. Research on the thermal ecology of reptiles indicates some of the important ways in which snakes are likely to be affected by global warming. For example, snakes display considerable plasticity in life-history traits. In response to increased food intake, snakes can grow faster, mature at larger sizes, and be more fecund $[9,10]$. Warmer climates are likely to affect food intake by altering digestion times, the length of time snakes can forage per day, and the number of foraging days per season. Global warming seems likely to have similar direct and indirect effects on most aspects of snake behavior and ecology.

Most of what we know about how climate change has already affected animal populations comes from longterm studies conducted for reasons other than to document climate change effects $[6,7,11,12]$. For example, birds are migrating earlier Bradley, et al. [13] and nesting earlier Dunn and Winkler [14], and butterflies are appearing earlier in the spring and shifting their ranges northward. Thus far, only a handful of studies have been published documenting climate change effects on ectothermic vertebrates
$[15,16]$, and none of these is on snakes. Weatherhead, et al. [17] did document a long-term decline of Pantherophis spiloides that appeared to be climate driven, but they were unable to identify the specific climate features that were responsible. Clearly, snake biologists need to be more aggressive in using their long-term data sets to identify population trends and determine if these trends are associated with changes in climate.

The first step in predicting how populations will be affected by climate change is to determine how they respond to contemporary climate variation. In general, we expect that if conditions become warmer, both the costs and benefits of thermoregulation should decrease for temperate-zone snakes. This should allow snakes either to thermoregulate more effectively or to spend less time thermoregulating, either of which should be beneficial. Available evidence is indirect but consistent with this expectation. European Adders (Vipera berus) grow faster in years with warmer, sunnier active seasons [9]. Aspic Viper (Vipera aspis) population dynamics appear to be driven by juvenile survival, which in turn varies strongly with winter weather [18]. Variation in temperature during the active season affected growth and, thus, age at maturity of watersnakes Nerodia [19]. Substantial overwinter mortality of Red-sided Gartersnakes (Thamnophis sirtalis parietalis) was attributed both to flooding and to freezing associated with light snow cover [20]. The fact that snakes control their body temperatures behaviorally should make it easier for them to adjust to warming climates. At some point, however, conditions could become too warm for snakes to adjust behaviorally. Local extirpation and range shifts will be the likely outcome $[8,21]$. Snakes are fascinating to many laypeople and scientists alike, and numerous studies of snake ecology and natural history have been conducted. For nearly all snake species, however, a comprehensive understanding of their ecology and biology is lacking. Such gaps in our knowledge limit our ability to develop effective conservation and management strategies or, more often, prohibit arguments that conservation is needed at all. This study was aimed at examining the role that weather condition plays on the ecological niche of snakes in Bertoua forest area.

\section{Materials and Methods}

\section{Description of the study area}

Bertoua is the capital of Eastern Region of Cameroon, with a land surface area of $100 \mathrm{~km}^{2}$ and a human 


\section{Journal of Ecology \& Natural Resources}

population of about 95000, it is well known in timber wood and mining exploitations. Geographically, Bertoua is located on latitude $4^{\circ} 35^{\prime} 0^{\prime \prime}$ north and longitude $13^{\circ} 41^{\prime} 0^{\prime \prime}$, east (Figure 1). The climate is described as wet equatorial climate (also known as a Guinea type climate), meaning that it experiences high temperatures $\left(24^{\circ} \mathrm{C}\right.$ on average). The climate is greatly influenced by the monsoon and Harmattan winds resulting in four characteristic seasons: a long dry season from December to May, a light wet season from May to June, a short dry season from July to October, and a heavy wet season from October to November. Humidity and cloud cover are relatively high, and precipitation averages $1500-2000 \mathrm{~mm}$ per year [22,23]. The vegetation type in the study site is described as semi-deciduous Guinea-congolaise dense tropical rainforest and is characteristically a mixture of evergreen forest and semideciduous forest which is stratified into several layers. In this forest type, trees can grow as tall as $70 \mathrm{~m}$ and as big as $150 \mathrm{~cm}$ in diameter or more. Available literature indicates that the species richness and diversity in this area is very high; about 1500 different plant species grow in the area [22].

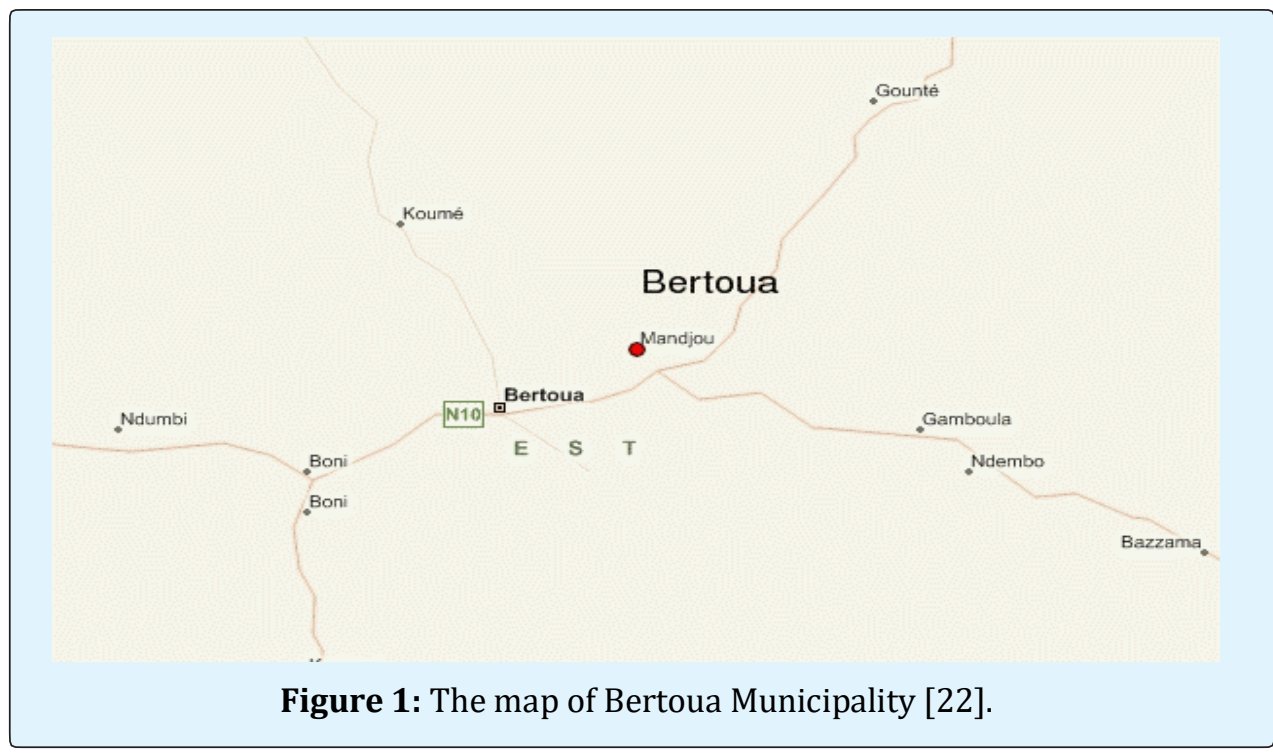

Although there are no specific studies on wildlife in Bertoua, literature on the East Region of Cameroon indicates that this region is very important in terms of its diversity and abundance of wildlife resources, testified by the creation of many protected areas in this Region. The region contains a variety of large mammals, small mammals, and avifauna. Large mammal populations include threatened species listed on the IUCN Red list of species, such as elephants (Loxodonta africana cyclotis), chimpanzees (Pan troglotydes), gorillas (Gorilla gorilla), buffalos (Syncerus caffer nanus), giant pangolins (Manis gigantea) antelopes (Panthera pardus). The population of small mammals is dominated by numerous species of monkeys and rodents, including: Cercopithecus spp, Antherurus africanus, Cephalobus spp, Tragelaphus spekki and Colobus guereza. The avifauna population is dominated by dense forest species, including globally threatened species such as Bradypterus grandis, Lobotos oriolinus, Pteronetta hartlaubii and many other bird species $[22,23]$.

\section{Data Collection}

The data collection started with a brief pilot study to test the methods in the study area. The research team comprised of 10 local farmers who took interest in the research topic and decided to volunteer in its field data collection program. This team was divided into five groups, deployed to different forest areas of the municipality for snake observation. The observation of snakes in the study area was done for one month from 7:30 am - 5:30 pm each day. Additionally, all the observers were dressed in protective shoes and clothes to avoid snakebites. Radom spot observations were done on forest, grassland, streams, and farmlands [24]. Every snake or snake sign encountered during this process was recorded in the check-sheet by each observer. This survey recorded 444 snake encounters, and the species encountered were black cobras (Naja melanoleuca), green mambas (Dendroaspis viridis), vipers (Bitis gabonica), green-tree snakes (Dendrelaphis punctulatus), small brown snakes (Dendrelaphis shokan),and python (Python regius). 


\section{Journal of Ecology \& Natural Resources}

\section{Data Analysis}

The research data was analyzed by the use of SPSS statistical tool. Variables such as snake species, weather condition, landscape, and photo-period were statistically tested to have a comprehensive knowledge on their degree of association. The results obtained from this statistics were hence displayed on figures and pie-chats.

\section{Results}

This survey revealed an ecological relationship between weather condition and various species of snakes in the study area, $\chi^{2}=11.244 \mathrm{df}=10, \mathrm{P}<0.05$ (Figure 2). Weather, is an ecological factor crucially indicating the welfare of wildlife in the wild environment. Additionally, weather conditions determine the floral and faunal species diversity in the wild. The geographic location and distribution of species on the earth planet varies continentally due to weather diversification. In wildlife ecology, weather is an indispensable factor for the survival of biodiversity, the reason for which much research interest on wildlife study is tilted towards it. The relationship between the various snake species and different weather conditions in the study area has shown the importance of the later in determining the population distribution of this animal species. The three different conditions, sun, rain, and wind taken into consideration, revealed an encounter rate of all the snake species, highest in the sunny weather $88.3 \%$ and least in the rainy weather $5.4 \%$ (Figure 3). This justifies that the sunny weather is preferable for snakes, for their physiological metabolism activities.

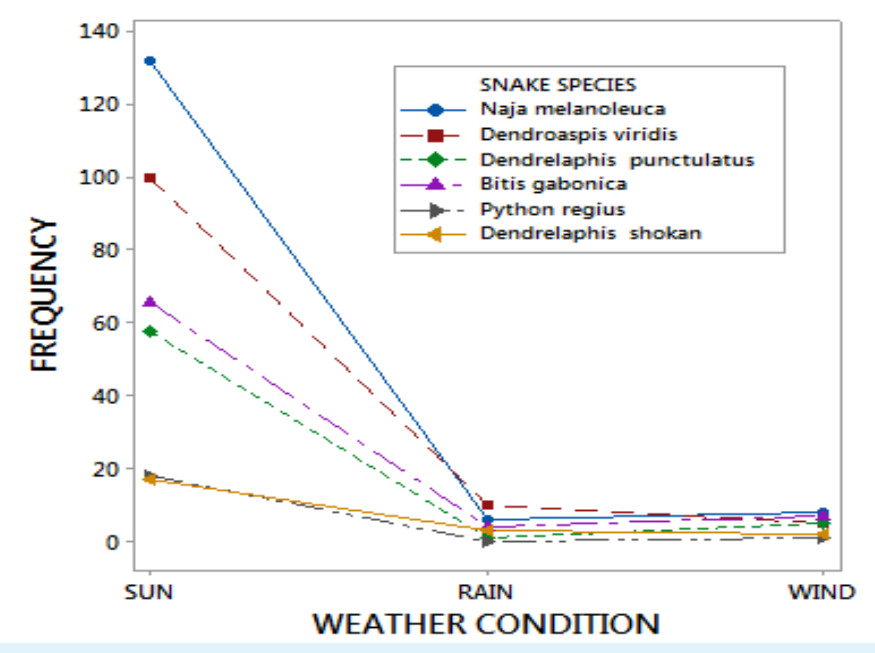

Figure 2: Weather conditions and the snake species.

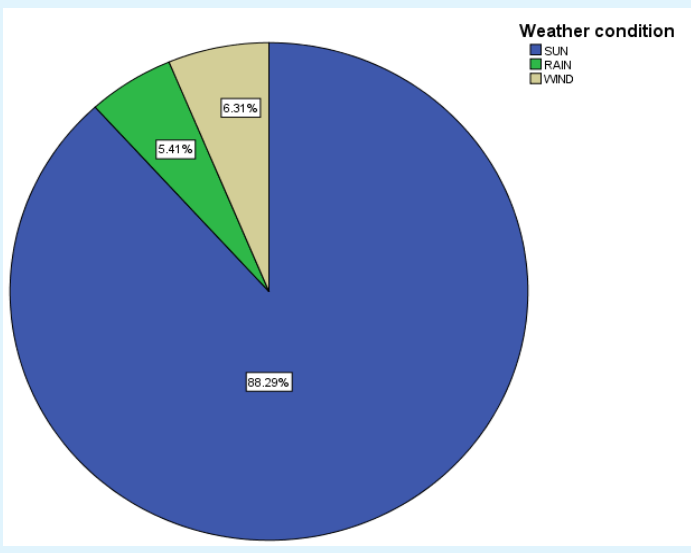

Figure 3: Weather condition.
Besides, the results revealed an association between landscape and snake species $\chi^{2}=21.142 \mathrm{df}=15 \mathrm{P}<0.05$ (Figure 4). Species niche preference is an important factor in snake ecology, for this reason this research considered four different wildlife niches, the farmland, slope forest, stream, and swamp. All these areas are known to be used by all species of snakes in the study area; however, the flat-land area recorded the highest snake encounter rate $77.48 \%$ while the swamp had $2.48 \%$ (Figure 5). The flat area preference for these snakes in the study area might be due to food accessibility and availability, such as mice, rodents, toads, and frogs. Snakes, like other wildlife species have niche priority for food and safety, a key reason for the crop-farming area choice in this study area. Bertoua municipality has an undulating surface area, flat in most areas, another reason for the snake adaptation for 
this landscape niche. A flat landscape surface in the wild would facilitate the movement of wild animals such as

snakes than the steep slopes and escapement areas.

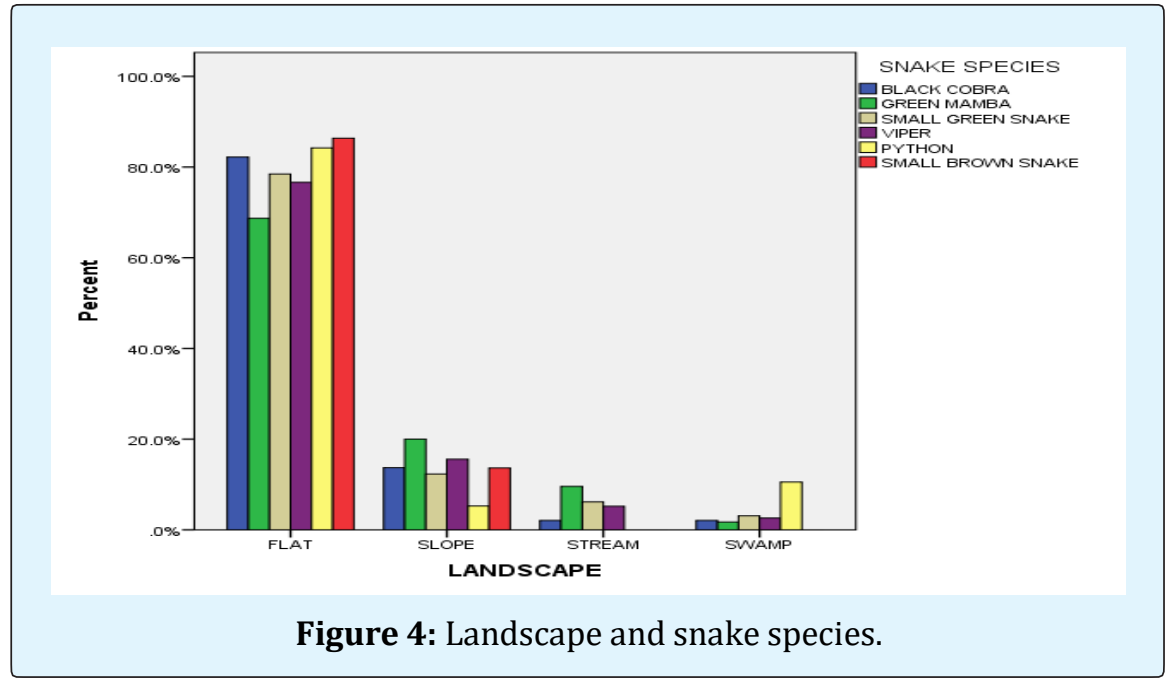

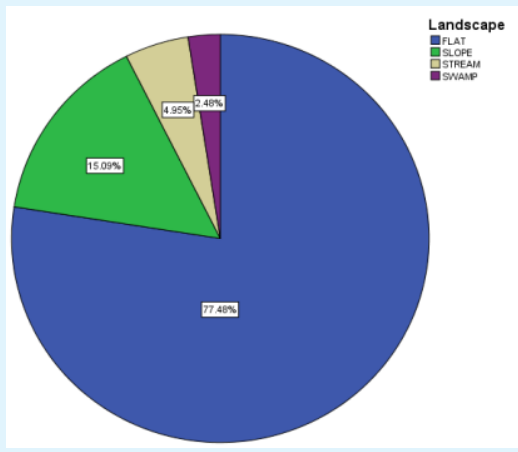

Figure 5: Landscape type.

The photo-period has shown a significant association on weather condition as well, $\chi^{2}=8.907 \mathrm{df}=4, \mathrm{P}<0.05$
(Figure 6). Reptiles are ectodermic in nature; hence seek always for a warmer environment for acquisition of heat into their body systems. Most areas in the Eastern Region of Cameroon are rich in the rainforest, experiencing much warmness in the dry seasons of the year and coldness in the wet seasons. This climatic state of this eco-region is however translated into a huge floral and faunal richness of the area. Nevertheless, snake encounter rates in the study area were most common during the sunny afternoon weather. An afternoon bright weather condition would trigger a thermoregulation adjustment into the body physiological of the snakes, a mechanism necessary for the reptiles to adjust and fix up their body metabolism activities.

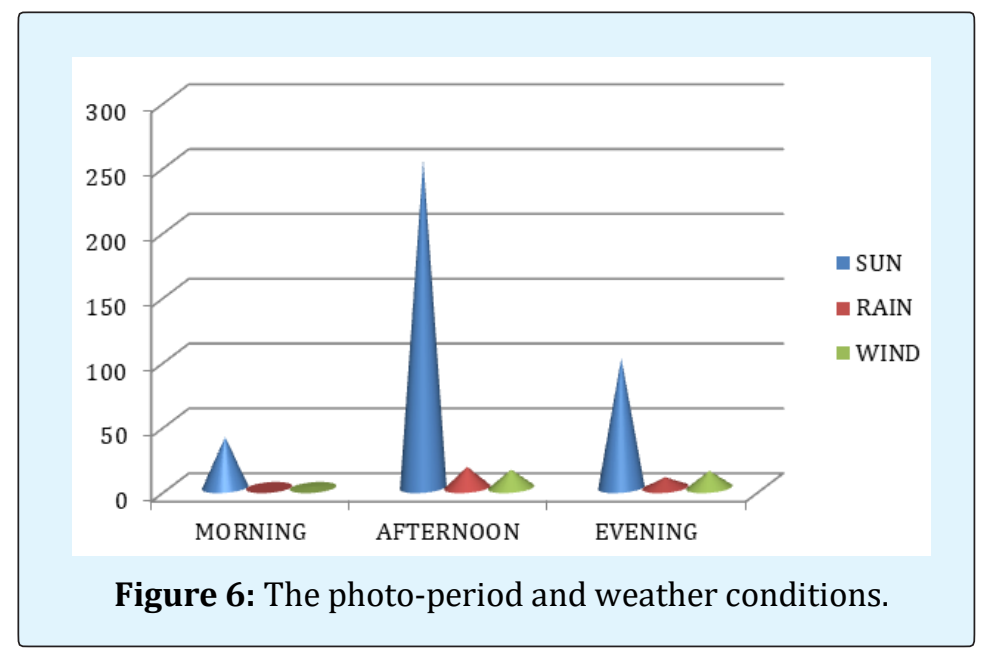


The location of snakes significantly associated with the species, $\chi^{2}=191.344 \mathrm{df}=5, \mathrm{P}=0.00$ (Figure 7). Snakes, like other wildlife species are either arboreal, grounddwelling or both. Most of the snakes encountered were on the ground $87.16 \%$ (figure 8). The green mamba (Dendroaspis viridis) was the dominant snake species encountered on trees, an adaptation to its feeding ecology. Green mambas are also known to feed on birds on trees, which might be one of the reasons for their arboreal behavior in the wild. However, it should be noted that most snakes are partially arboreal, though most feed on the ground, especially on rodents in burrows. In cropland areas where these snakes where most encountered, are known to have a rich feeding ecology, ranging from mice to duikers eating crops in farms.

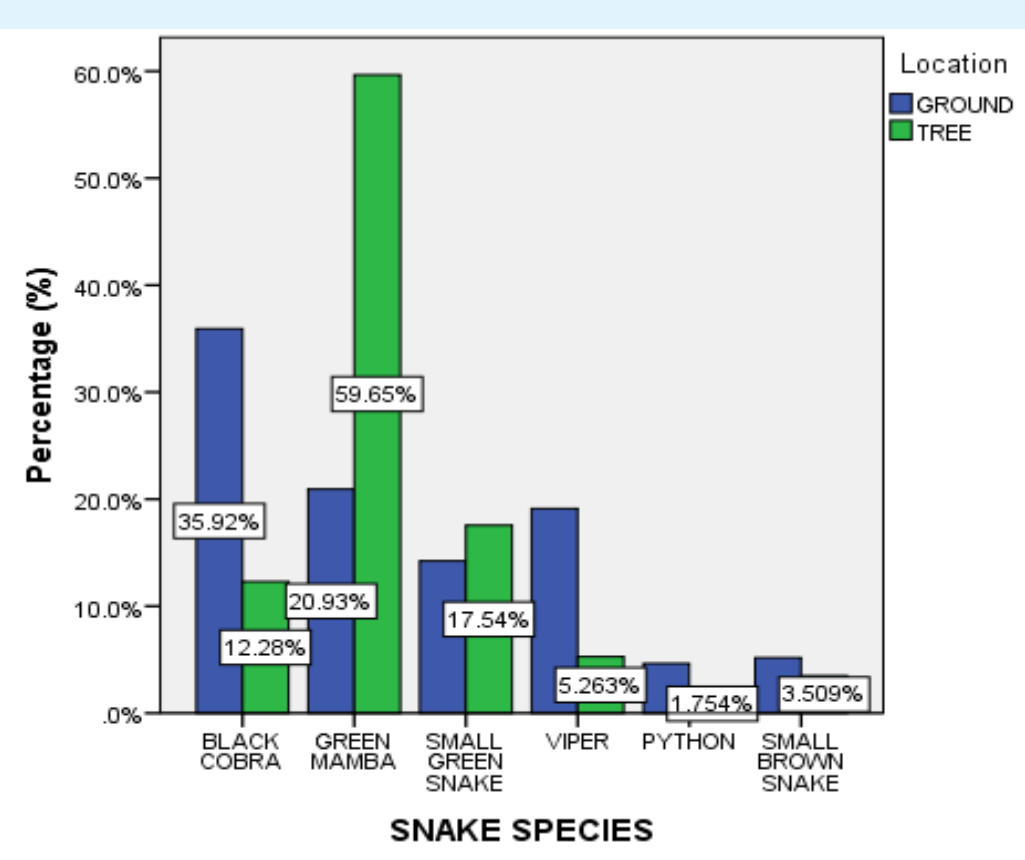

Figure 7: Snake species and location.

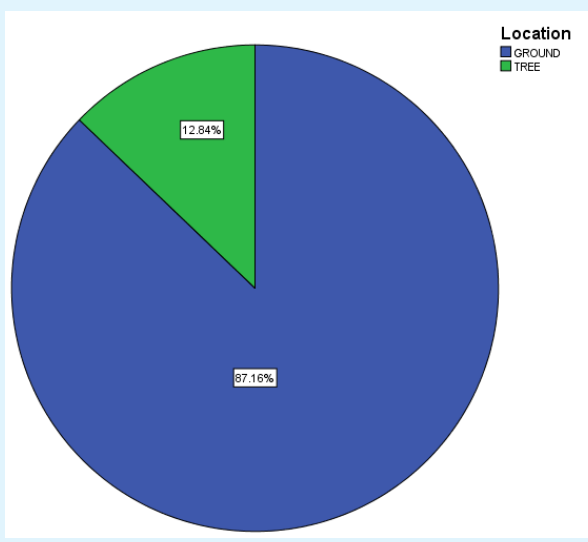

Figure 8: Location of Snakes.
Furthermore, the snake location and weather condition revealed a significant link, $\chi^{2}=5.546 \mathrm{df}=2$, $\mathrm{P}<0.05$ (Figure 9). The sunny weather condition witnessed a very significant observation of snakes on the ground than on trees. The cropland areas where most snakes were observed have fewer trees than the neighboring fallowing secondary vegetation. The thermal ecology of snakes is characterized with a moderate temperature, an ecological condition which facilitated their observations. A bright sunny atmosphere created a conducive environment for these cold-blooded animals to acquire body warmness, a moderate energy source to run body physiological activities. 


\section{Journal of Ecology \& Natural Resources}

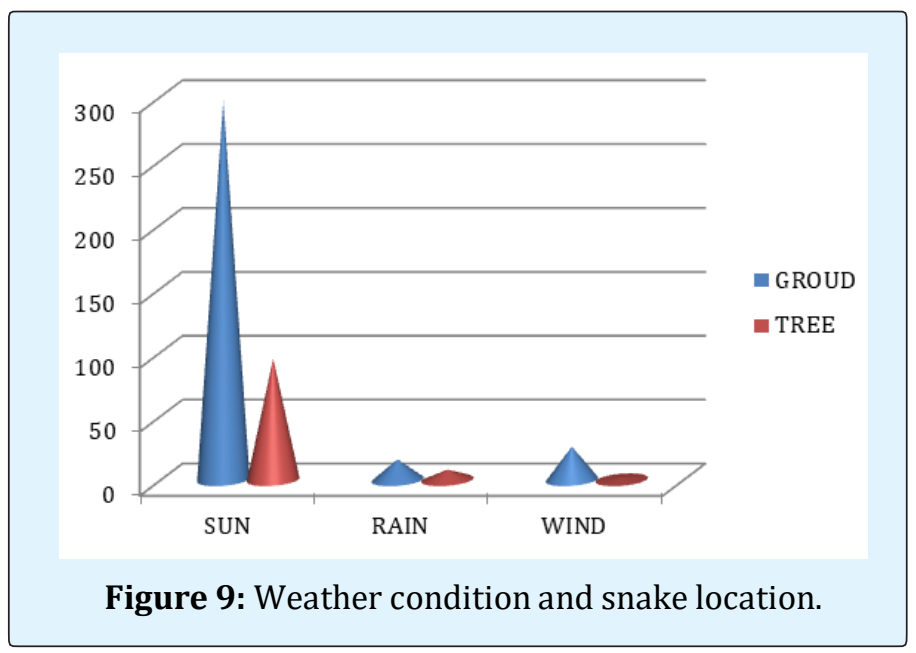

Weather condition and landscape has shown a significant dependency, $\chi^{2}=41.316 \mathrm{df}=6, \mathrm{P}=0.00$ (Figure 10). The landscape is another ecological factor determining wildlife niche and population distribution in the wild. The thermal environmental condition plays an important role in the welfare and survival of the serpents in all parts of the world except in the polar eco-zones because of severe hypothermic environmental conditions

preventing these wild animals to regulate their internal body temperature. The rainy and windy environmental conditions witnessed the least snake encounter observations; this is mainly due to the atmospheric temperature reduction forcing these reptiles into burrows, nests, and litter-covers, areas believed to be warmer than the open environment.

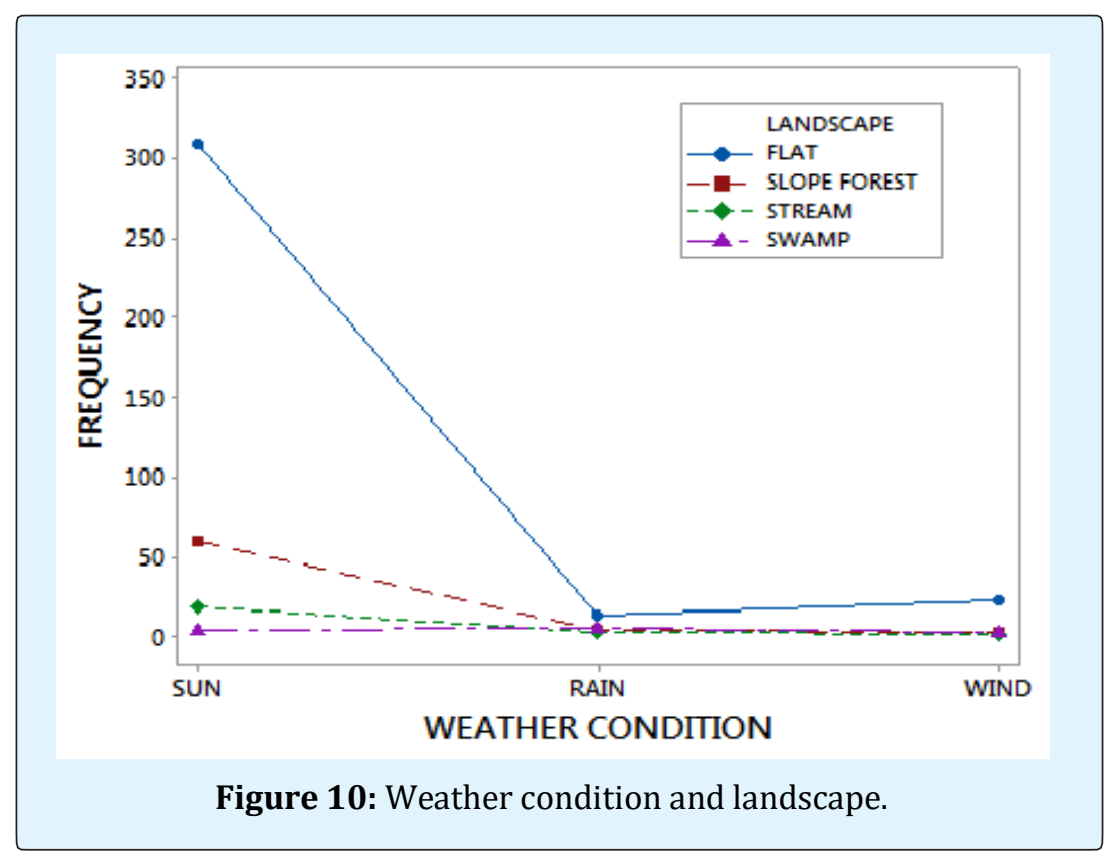

\section{Discussion}

Temperature determines the rate of almost all biological processes in snakes, including demographic traits such as growth rates, ages at attainment of sexual maturity, energy acquisition rates, and reproductive frequencies [25]. Thus, we can confidently predict that snake populations in relatively cold climates will tend to have slower life histories, hence, lower rates of population recovery after any crash than genetically 
similar populations inhabiting warmer climates that allow longer activity seasons each year. For example, female Aspic Vipers (Vipera aspis) reproduce on an approximately1-year cycle in southern Europe, but are biennial in their northern distribution in France Zuffi, et al. [26] and triennial in the Alp mountains. Thus, the sustainable level of harvesting from wild populations will likely be higher, as a general rule, for tropical taxa than for temperate-zone species [20,27]. Other factors exacerbate this vulnerability of cool-climate populations, notably the higher incidence of viviparous rather than oviparous reproduction, hence, a reduced clutch frequency per female. Gravid females also tend to select more exposed positions, thus, increasing their vulnerability to predators because of the difficulty of maintaining optimally high incubation temperatures for their developing embryos.

Reptiles are found in a range of diverse environments from the arctic to the equator. Their success and dispersion is dependent on access to external heat sources for their internal processes to operate sufficiently such as homeostasis [28]. There is diversity between species of reptile and their tolerance to different temperatures, in warmer climates temperature produces more generalist reptiles as temperature regulation is of lower importance. In comparison, reptiles in cooler climates face a difficult battle with temperatures and are more specialist in their ability to thermoregulate [29]. Reptiles are poikilothermic and rely on their environment as a source of heat to raise their body temperature. This is controlled via behavioral processes and these vary depending on the environment they are in. In species of reptiles that have the ability to alter skin coloration such as chameleons, and geckos they can produce darker colors to increase the absorption of early morning sun. This behavior allows them to reach optimal temperatures faster and also reduces the amount of time spent in the open which leaves them vulnerable to predation [30]. Optimal temperatures allow the reptile to function and metabolize, however, lower temperatures can slow processes down. Typically the metabolic rate is $10 \%$ of the equivalent size endotherm, this is an example of the low cost energy needed to sustain an ectotherm [31].

Reptiles' low metabolic rate and various unique physiological attributes have enabled them to adapt to some of the harshest environments e.g. a high temperature habitat such as deserts. Although deserts are hot throughout the day and can possibly reach temperatures of $50^{\circ} \mathrm{C}+$, they can at night have temperatures that drop to zero temperatures or around $5^{\circ} \mathrm{C}$ in the Sahara. Reptiles have a varied climate to contend with, including the need to maintain correct temperatures in extreme heat but also surviving the cold nights. Therefore sunrise is a prime time for reptiles to warm from the previous cold night. Many species have adaptations that utilize color change to rapidly increase body temperature. Walton \& Bennett [30] studied the behavioral alteration of skin color in species of reptile such as the chameleon to increase body temperature and reduce time spent in vulnerable basking locations. Aguilar \& Cruz [32] research revealed that the quality of the daytime refuge is an important factor of nocturnal activity performance. Depending on how warm the refuge is will directly affect their performance during activity. Nocturnal reptiles are thigmothermic, they attain their heat from surrounding substratum rather than basking under the sun. Throughout the day the substratum temperature is maintained at a higher temperature from the sun even after dusk; during this time nocturnal reptiles become active absorbing heat from their environment. Nocturnal species are more tolerant to low temperatures in comparison with diurnal species [32].

Although more associated with hot climates, reptiles, in some species have acclimatized to living in colder environments. Species such as the European adder (Vipera berus), is distributed across temperate regions of Europe and Asia. They show a tolerance to cold environments and can be found as north as the Arctic Circle. Work conducted by Guisan \& Hofer [33] show that although reptiles can inhabit harsh environments, their success may be due to the ability to inhabit areas with beneficial sunlight capture, angle and substratum, therefore producing a suitable microclimate for them to survive. Behavior is a significant feature of thermoregulation but other physiological attributes aid in adapting to these environments. Small size allows the reptiles to gain larger benefits from short periods of sunlight allowing some reptiles to attend optimal temperatures quickly. To escape colder winter months they enter hibernation choosing beneficial hibernacula. The adder was categorized as virtually non freeze tolerant capable of surviving only a short exposure, not colder than approximately $4^{\circ} \mathrm{C}$ [34]. Super-cooling could play a role in winter survival but their precise choice of hibernation site is probably the most important.

\section{Conclusion}

Reptiles are considered one of the most successful organisms on the planet due to their hardiness to survive and adapt to ever changing extreme environments. They harness diverse adaptations from using cryoprotectants to survive harsh winters, and sacrificing vital water to 
decrease the body in intolerable temperatures. In sub Sahara Africa, the ecological distribution of snakes is known to be influenced by environmental temperature, the reason for which in this study, more snake encounters were recorded in the bright sunny mid-day weather condition when the temperature was relatively high. Snakes in the forest area of Bertoua were most observed in sunny weather condition in all the landscapes, locations, and vegetations. This study recommends a withdrawal of human-forest activities such as farming and fuel-wood gathering during a mid-day bright sunny weather condition to avoid snake encounters that may provoke conflicts.

\section{References}

1. Peterson CR, Gibson AR, Dorcas ME (1993) Snake thermal ecology: The causes and consequences of body-temperature variation. In: Seigel RA, Collins JT (Eds.), Snakes: Ecology and behavior. New York: McGraw-Hill, pp: 241-314.

2. Huey RB (1982) Temperature, physiology, and the ecology of reptiles. In: Gans C, Pough FH (Eds.), Biology of the Reptilia, New York: Academic Press, 12: 25-91.

3. Reinert HK (1993) Habitat selection in snakes. In: Seigel RA, Collins JT (Eds.).

4. Shine R, Madsen $T$ (1996) Is thermoregulation unimportant for most reptiles?: An example using water pythons (Liasis fuscus) in tropical Australia. Physiol Zool 69(2): 252-269.

5. Gaston KJ (2003) The structure and dynamics of geographic ranges. Oxford, U.K.: Oxford University Press.

6. Hughes L (2000) Biological consequences of global warming: Is the signal already appar-ent? Trends Ecol Evol 15(2): 56-61.

7. McCarty JP (2001) Ecological consequences of recent climate change. Conserv Biol 15(2): 320-331.

8. Currie DJ (2001) Projected effects of climate change on patterns of vertebrate and tree species richness in the coterminous United States. Ecosystems 4(3): 216225 .

9. Lindell LE (1997) Annual variation in growth rate and body condition of Adders, Vipera berus: Effects of food availability and weather. Can J Zool 75(2): 261270.

10. Luiselli L, Capula M, Shine R (1997) Food habits, growth rates, and reproduc- tive biology of Grass Snakes, Natrix natrix (Colubridae) in the Italian Alps J Zool 241(2): 371-380.

11. Walther GR, Post E, Convey P, Menzel A, Parmesan C, et al. (2002) Ecological responses to recent climate change. Nature 416: 389-395.

12. Krajik K (2004) All downhill from here? Science 303: 1600-1602.

13. Bradley NL, Leopold AC, Ross J, Huffaker W (1999) Phenological changes re-flect climate change in Wisconsin. Proc Nat Acad Sci USA 96(17): 9701-9704.

14. Dunn PO, Winkler DW (1999) Climate change has affected breeding date of tree swallows throughout North America. Proc Biol Sci 266(1437): 2487-2490.

15. Pounds JA, Fogden MPL, Campbell JH (1999) Biological response to climate change on a tropical mountain. Nature 398: 611-615.

16. Gibbs JP, Breisch AR (2001) Climate warming and calling phenology of frogs near Ithaca, New York, 1900-1999. Conserv Biol 15(4): 1175-1178.

17. Weatherhead PJ, Blouin-Demers G, Prior KA (2002) Synchronous variation and long-term trends in two populations of Black Rat Snakes. Conserv Biol 16(6): 1602-1608.

18. Altwegg R, Dummermuth S, Anholt B, Flatt T (2005) Winter weather affects Asp Viper Vipera aspis population dynamics through susceptible juveniles. Oikos 110(1): 55-66.

19. Brown GP, Weatherhead PJ (2000) Thermal ecology and sexual size dimorphism in Northern Water Snakes, Nerodia sipedon. Ecol Monogr 70(2): 311330.

20. Shine R, Harlow P, Keogh JS, Boeadi (1995). Biology and commercial utilization of acrochorid snakes with special reference to karung (Acrochordus javanicus). J Herpetol 29(3): 352-360.

21. Kling GW, Hayhoe K, Johnson LB, Magnuson JJ, Polasky S, et al. (2003) Confronting climate change in the Great Lakes region: Impacts on our communities and ecosystems. Cambridge, Mass.: Union of 
Concerned Scientists/ Washington, D.C.: Ecological Society of America.

22. SEBC (2002) Plan D'Aménagement De L'UFA 10-007. Societé d'exploitation des Bois du Cameroun, BP 2064, Douala, Cameroun.

23. SEFAC (2005) Concession Forestière $n^{\circ} 1052$ : UFA 10 008: Rapport D'Inventaire D'Aménégement. SEFAC, BP 942, Douala, Cameroon. Snakes: Ecology and behavior, New York: McGraw Hill, pp: 201-240.

24. Crump \& Scott, Crump M, Scott NJ (1994) Visual encounter survey. In: Heyer W, Donelley MA, McDiarmid RA, Hayek LC, Foster MC (Eds.), Measuring and monitoring biological diversity: standard methods for amphibians. Smithsonian Institution Press; Washington, D.C.: 1994. Pp: 84-92.

25. Adolph SC, Porter WP (1993) Temperature, activity, and lizard life-histories. Am Nat 142(2): 273-295.

26. Zuffi MAL, Giudici F, Ioale P (1999) Frequency and effort of reproduction in female Vipera aspis from a southern population. Acta Oecologica 20(6): 633-638.

27. Shine R, Ambariyanto, Harlow PS, Mumpuni (1999b) Reticulated pythons in Sumatra: biology, harvesting and sustainability. Biological Conservation 87(3): 349-357.

\section{Journal of Ecology \& Natural Resources}

28. Spellerberg IF (1973) Critical Minimum Temperatures of Reptiles. In: Wieser W (Ed.), Effect of Temperature on Ethodermic Organisms. SpringerVerlag Berlin, pp: 239-247.

29. Segura C, Feriche M, Pleguezuelos JM, Santos X (2007) Specialist and generalist species in habitat use: implications for conservation assessment in snakes. J Nat Hist 41(44): 2765-2774.

30. Walton BM, Bennett AF (1993) Temperaturedependent color change in Kenyan chamaleons. Physiol Zool 66(2): 270-287.

31. Schmidt-Nielsen K (1964) Desert animals. Physiological problems of heat and water. Oxford University Press, London.

32. Aguilar R, Cruz FB (2010) Refuge use in a Patagonian nocturnal lizard, Homonota darwini: the role of temperature. J Herpetol 44(2): 236-241.

33. Guisan A, Hofer U (2003) Predicting reptile distributions at mesoscale: relation to climate and topography. J Biogeography 30(8): 1233-1243.

34. Anderson S, Johansson L (2001) Cool Hardiness in the Boreal Adder, Vipera berus. Cryo Letters 22(3): 151156. 